Portland State University

PDXScholar

\title{
Street Portals: Urban User Interface 'Test Bed' Prototype for Bike Shares
}

Jason Germany

University of Oregon

Philip Speranza

University of Oregon

Follow this and additional works at: https://pdxscholar.library.pdx.edu/trec_reports

Part of the Transportation Commons, Urban Studies Commons, and the Urban Studies and Planning Commons

Let us know how access to this document benefits you.

\section{Recommended Citation}

Germany, Jason and Philip Speranza. Street Portals: Urban User Interface 'Test Bed' Prototype for Bike Shares. NITC-SS-738. Portland, OR: Transportation Research and Education Center (TREC), 2014. https://doi.org/10.15760/trec.29

This Report is brought to you for free and open access. It has been accepted for inclusion in TREC Final Reports by an authorized administrator of PDXScholar. Please contact us if we can make this document more accessible: pdxscholar@pdx.edu. 


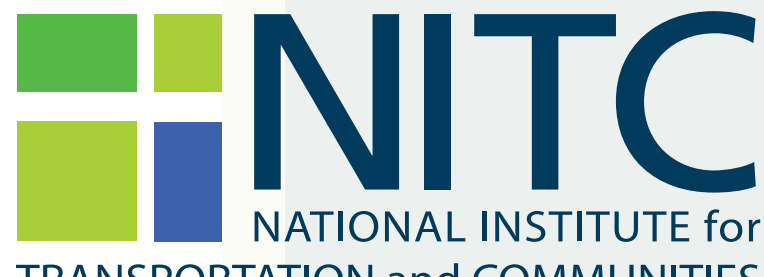

TRANSPORTATION and COMMUNITIES

\section{FINAL REPORT}

\section{Street Portals: Urban User Interface 'Test Bed' Prototype For Bike Share}

NITC-SS-738 June 2014

NITC is the U.S. Department of Transportation's national university transportation center for livable communities.

\#":- TREC 


\title{
STREET PORTALS \\ URBAN USER INTERFACE 'TEST BED' PROTOTYPE FOR BIKE SHARE
}

\section{Report Type}

NITC-SS-738

by

Jason Germany and Philip Speranza

University of Oregon

\author{
for \\ National Institute for \\ Transportation and Communities (NITC) \\ P.O. Box 751 \\ Portland, OR 97207
}
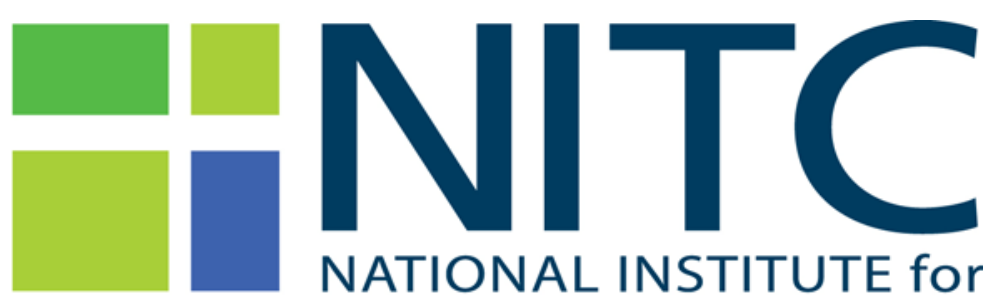

TRANSPORTATION and COMMUNITIES

June 2014 


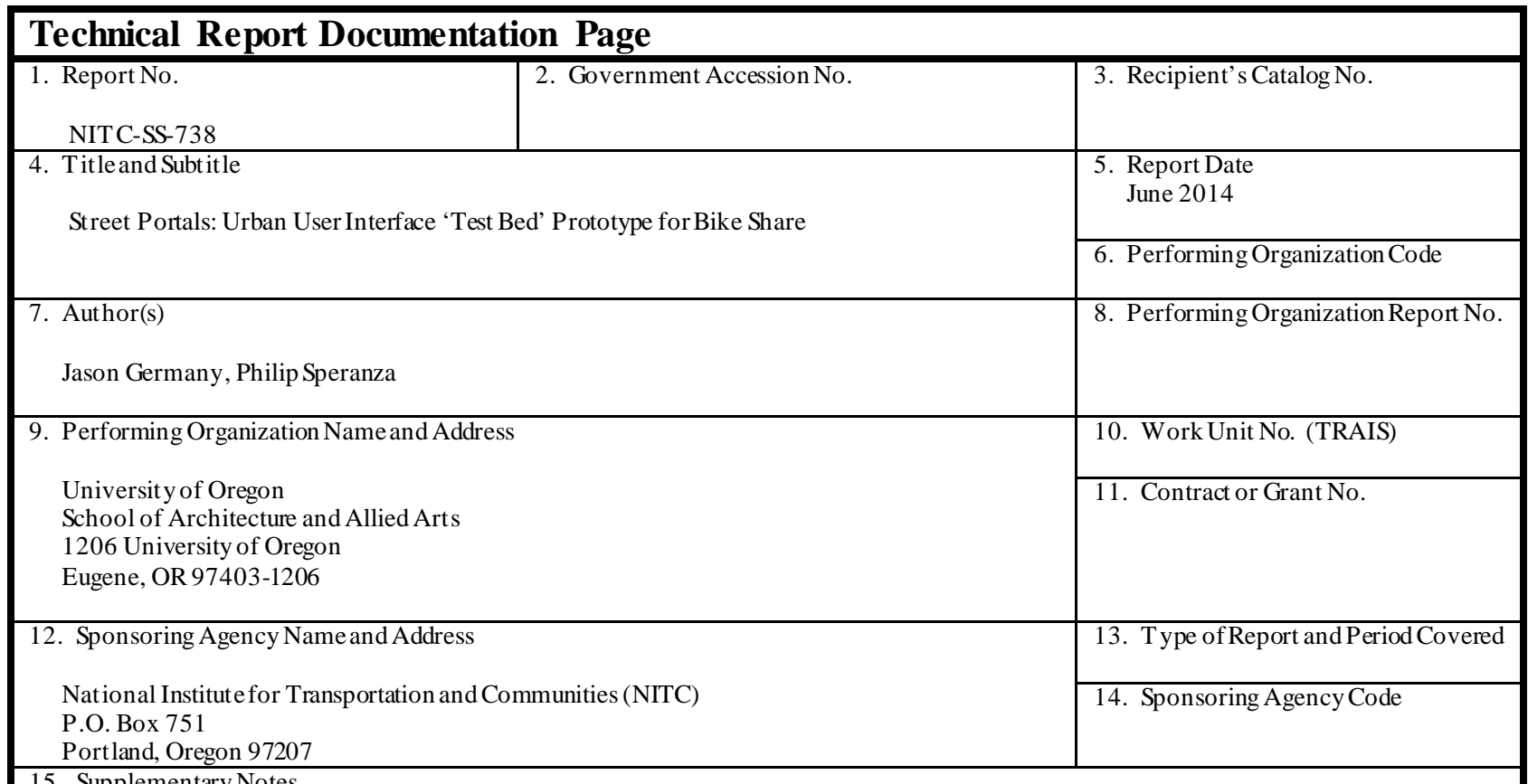

15. Supplementary Notes

\section{Abstract}

The objective of this research project is to develop a user interface "test bed" to measure the role of touchscreen kiosks with community connectivity. This interface test bed will apply the knowledge of interface design to the domain of public transit kiosks, with a particular focus on bike share stations. The value of this research is the ability to generate user feedback bet ween community members using urban experiences. Safety, effectiveness and community connectivity of public transit is enhanced with this information interface.

This report explains the test bed kiosk's design, physical build, and hardware and software testing. User interaction studies for standards, accessibility and design criteria were done; 2D and 3D modeling, material sourcing and mockups were built. Hardware sensors for proximity included passive infrared (PIR), ultrasonic range finding and RGB-D technology using Microsoft Kinect. Tests measured interaction with user movement type, including the differentiation of pedestrians, cyclists and vehicles. Observed interaction tests were performed with human subjects review approval.

The interface test bed will allow for future tests using more advanced sensors and include user intercept surveys. The prototype test bed is a tool to test interface design for connecting urban design theory classifying urban experience information to enhance transit, firstly through the specific application of public bike share.

\section{Key Words}

interaction design, urban design, community, connectivity, bike share

18. Distribution Statement

No restrictions. Copies available from OTREC: www.otrec.us

19. Security Classification (of this report)

Unclassified
20. Security Classification (of this page)

21. No. of Pages

Unclassified
22. Price 


\section{ACKNOWLEDGEMENTS}

This project was funded by the National Institute for Transportation and Communities (NITC). Invaluable contribution was provided by the strategic partnership with the University of Oregon Digital Scholars Center for the support of graduate research assistant Dan Anthony. Dan Anthony's dedication to the project ensured its success. We would like to thank the University of Oregon School of Architecture and Allied Arts, Dean Frances Bronet, Product Design Program Director Kiersten Muenchinger, and Department of Architecture Head Judith Sheine for their encouragement and support.

The authors would like to thank all the UO graduate and undergraduate students who have been involved in this research project and who have contributed to the founding efforts of the UO Urban Interactions Lab. Graduate student Dan Anthony provided daily work effort. Acknowledgement goes to the guidance of UO Sustainable Cities Initiative directors Marc Schlossberg and Nico Larco for their constructive comments and support before and during this research. The authors would like to thank all the contributors of this work with special acknowledgement to our mentors G.Z. Brown, James Tice and Karen Franck, who helped guide our path.

Software and coding acknowledgment goes to:

Map tiles by Stamen Design, CC BY 3.0

Map data by OpenStreetMap, CC BY SA

Processing sketches based on SimpleOpenNI, GNU GPL v2

\section{DISCLAIMER}

The contents of this report reflect the views of the authors, who are solely responsible for the facts and the accuracy of the material and information presented herein. This document is disseminated under the sponsorship of the U.S. Department of Transportation University Transportation Centers Program and the University of Oregon in the interest of information exchange. The U.S. Government and the University of Oregon assumes no liability for the contents or use thereof. The contents do not necessarily reflect the official views of the U.S. Government and the University of Oregon. This report does not constitute a standard, specification, or regulation 


\section{TABLE OF CONTENTS}

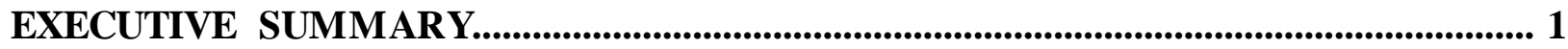

1.0 PROBLEM AND BACKGROUND ........................................................................ 2

1.1 PROBLEM: TRANSIT AND INTERFACE DESIGN............................................. 2

1.2 BACKGROUND: CITIES AND INFORMATION TECHNOLGY ................................2

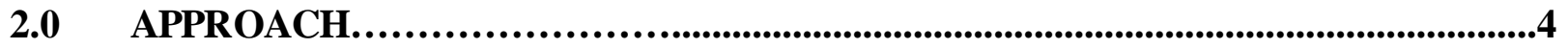

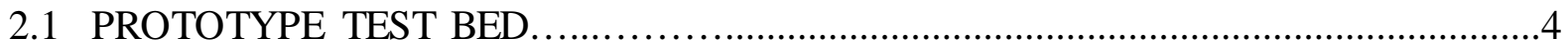

2.1.1 Design and urban experience..................................................................................4

2.1.2 Mockup, material sourcing and build.................................................................

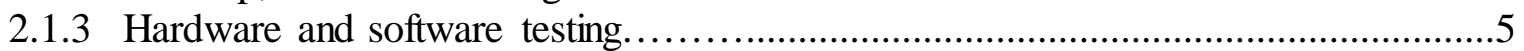

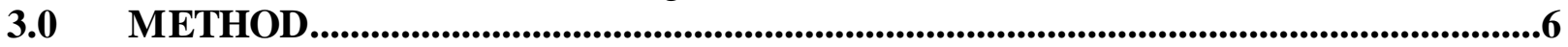

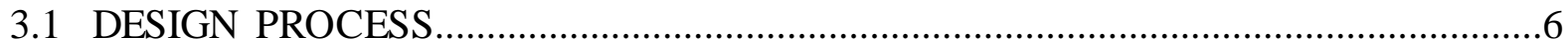

3.1.1 Interaction objectives for physical prototype............................................................ 6

3.1.1.1 Main criteria for prototype test bed.............................................................6

3.1.1.2 Current test bed design (prototype) - input/output system components.............. 7

3.1.1.3 Future test bed (prototype) - input/output system components ........................... 7

3.1.2 Accessibility and human factors...............................................................................

3.1.2.1 Test bed prototype fabrication...........................................................................................8

4.0 DATA COLLECTION.......................................................................................... 11

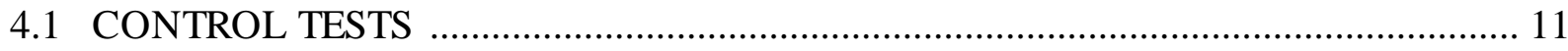

4.1.1 Sensor tests, in-lab and on-test stands ...............................................................11

4.1.1.1 Passive infrared motion detector (PIR).......................................11

4.1.1.2 Ultrasonic range finding ...............................................................................12

4.1.1.3 RGB-D camera (Microsoft Kinect).....................................................................12

4.1.1.4 Ongoing and future studies................................................................................14

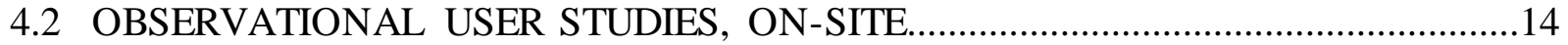

4.2.1 Pilot study: Observed interaction test.................................................................. 15

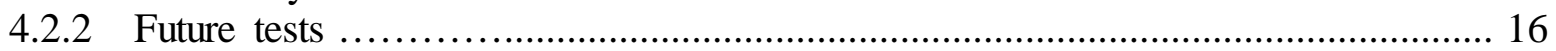

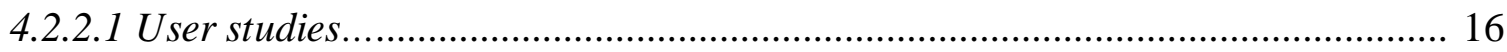

4.2.2.2 Identification of pedestrians, bikes and vehicles ................................................. 16

4.2.2.3 Urban design theory research...................................................... 16

4.2.2.4 Collaboration with municipal transit agencies......................................... 16

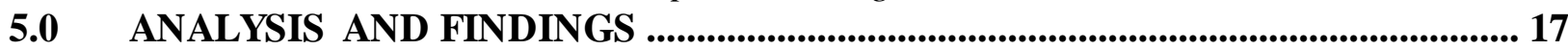

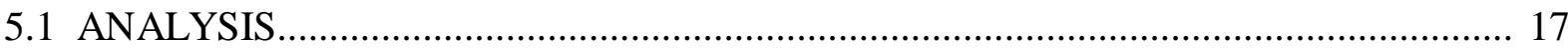

5.1.1 Design and build effectiveness.,........................................................................ 17

5.1.1.1 Design process............................................................................................... 17

5.1.1.2 Current design................................................................................................... 17

5.1.1.3 Future design, weather resistance, portability and other design criteria............ 17

5.1.2 Sensor effectiveness and future sensor criteria ..........................................................18

5.1.3 Subject interaction effectiveness................................................................................ 18

5.1.4 Location effectiveness and future deployment at urban transit location .................... 18

5.2 FINDINGS / CONCLUSION................................................................................ 18

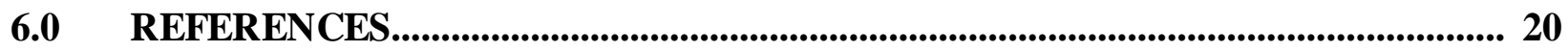

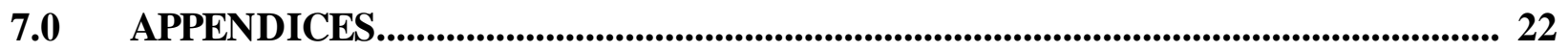




\section{EXECUTIVE SUMMARY}

The objective of this research project is to develop a user interface "test bed" to measure the role of touchscreen kiosks with community connectivity. This interface test bed will apply the knowledge of interface design to the domain of public transit kiosks, with a particular focus on bike share stations. The value of this research is the ability to generate user feedback between community members using urban experiences. Safety, effectiveness and community connectivity of public transit is enhanced with this information interface.

This report explains the test bed kiosk’s design, physical build, and hardware and software testing. User interaction studies for standards, accessibility and design criteria were done; 2D and 3D modeling, material sourcing and mockups were built. Hardware sensors for proximity included passive infrared (PIR), ultrasonic range finding and RGB-D technology using Microsoft Kinect. Tests measured interaction with user movement type, including the differentiation of pedestrians, cyclists and vehicles. Observed interaction tests were performed with human subjects review approval.

The interface test bed will allow for future tests using more advanced sensors and include user intercept surveys. The prototype test bed is a tool to test interface design for connecting urban design theory classifying urban experience information to enhance transit, firstly through the specific application of public bike share.

The development of the prototype test bed kiosk included the design, fabrication and testing for an open platform to understand interaction design and transit use. The investigation of a first proximity sensor allowed us to understand: 1) indoor lab versus outdoor public space differences of ambient conditions including light and glare and 2) user engagement of pedestrians and bike users in public spaces. The interaction with users was done using ultrasonic sensors to activate a more personal-scaled display of information. The overall successful operation of the user interaction pilot test proved the feasibility of developing an interactive kiosk to include ambient environmental conditions when interacting with transit users in public spaces. The study revealed important kiosk design criteria: 1) interactive display positioning; 2) sensor conditions; 3) user engagement; and 4) portability and weather resistance.

This research demonstrated the need to coordinate interactive design, computing and urban design in public spaces. Significant challenges were revealed in sensor type, managing fabrication-related timelines, and creating a custom-designed kiosk that allowed new instruments for measuring interaction of transit users in public spaces. However, the working prototype test bed and ability to swap out sensor arrays for successful engagement with passersby demonstrates the tool's future usefulness in providing information to public transit users and testing how community members may be connected through transit use in urban spaces. 


\subsection{PROBLEM AND BACKGROUND}

\subsection{PROBLEM:TRANSIT AND INTERFACE DESIGN}

Each day we are more and more dependent on digital information. Digital information has become an important infrastructure for transit systems and communities, but the user interface does not yet sufficiently make that information available to public transit users. Nor does it use participatory feedback to inform the efficiency, safety and user connectivity of transit. New research investigates how users "participate" rather than "be present" in urban computing (Greenfield and Shepard, 2007). Researchers have begun to enhance user interface with transit design using mobile phone signals to map private vehicular traffic (Cuff et al., 2008); NFC smart-card technology to measure commuter train use, crowd-sourced video and mobile phone signals to track and count pedestrians (Leber, 2014; Calabrese et al., 2011); and bike sensors onboard to enhance bicycle transit (Ratti, 2009). The lack of digital interface design at transit kiosks, especially for public bike share users, is a problem in a society where the up-to-date information and other transit information choices such as Google Maps, Apple's Siri and automated vehicles is ever increasing.
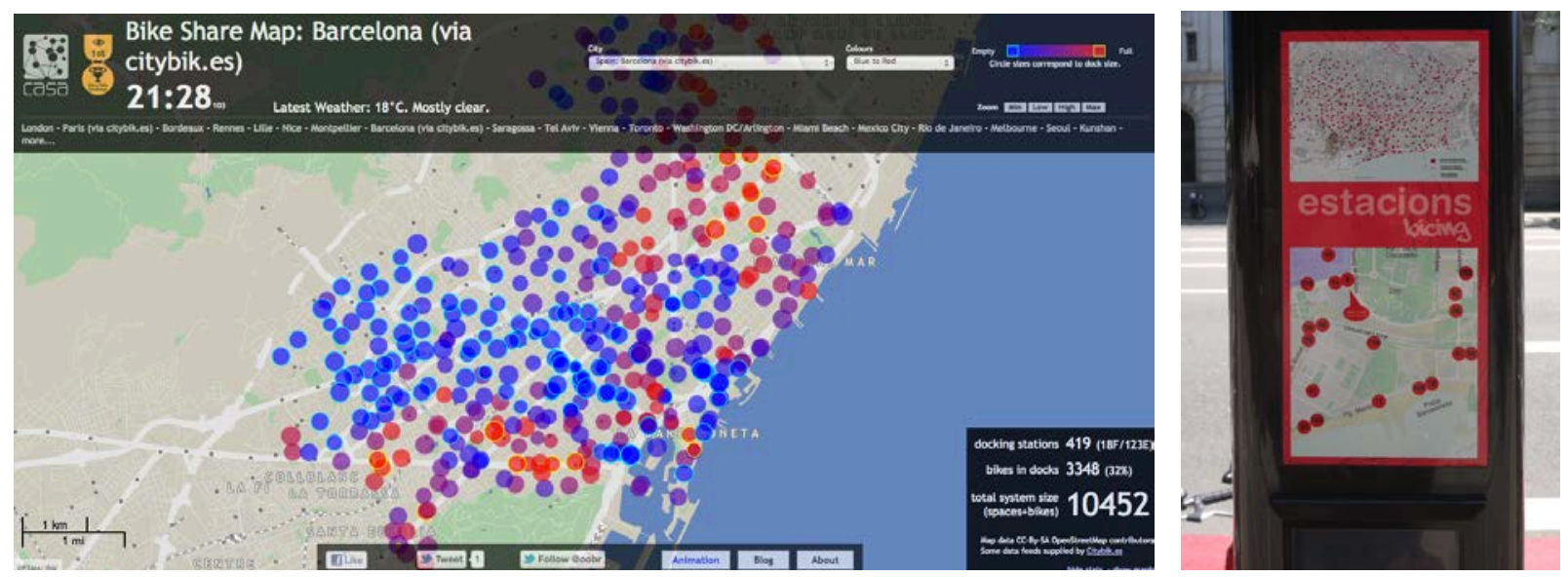

Figure 1.1: CASA Bartlett, Real-time Data of Barcelona Bike Share by Oliver Obrien (third-party using open API data)

Figure 1.2: Barcelona Bike Share Station, (fixed bike share map)

\subsection{BACKGROUND: CITIES AND INFORMATION TECHNOLOGY}

In 2010, more of the world's population began living in urban rather than rural environments (World Health Organization, 2014). This population shift - along with the emergence of the "smart city" (Shepard, 2011) and the use of information systems in cities to manage resources, infrastructure, optimization and community - has led to the growth of data density and diversity within these new environments. Brought on by improvements in sensing technology and the growth of information networks (Bowerman et al., 2000), the smart city has been championed by mayors, municipalities and private companies to address many of the $21^{\text {st }}$ century's problems related to climate change, energy consumption, transportation, pollution and economic growth. 
Rather than systems primarily being used as instruments for large-scale city administrators and consulting groups with the goal of optimization, there is a growing understanding among researchers to include small-scale stakeholders, namely the community and individual residents to act upon, direct or otherwise inform these information systems from the bottom up (Greenfield, 2013).

\section{User Experience and Bike Share}

To include users in urban data, researchers are focusing on the street level of user experience. Pedestrians may be provided a "platform for observing the environment and its dynamics as well as analyzing and criticizing it," (Nabian et al., 2012). Street-level transit users are required to check in to third-generation public bike share systems, requiring a moment of interface at the docking station. At this moment of interface and the ability to measure trip behaviors via GPS and system management, there exists the opportunity to make more transit information such as safe bike routes, efficient route planning and cultural events informed by individual and community participation. 


\subsection{APPROACH}

\subsection{PROTOTYPE TEST BED}

The development of a prototype test bed kiosk for public bike share was intended as a tool to understand the challenges of interface design in outdoor public spaces. This funded cycle of research focuses on the design, fabrication and testing of a physical kiosk. Initial tests include user activation. The prototype test bed in the future will serve as a valuable tool to test physical interface and gather data on user choices of urban experiences to inform safety, efficiency and community connectivity between users.

Public bike share is a unique transit interface between large-scale smart infrastructure and smallscale, time-sensitive phenomena. Bike share programs introduce a network of docking stations and kiosks that rent bikes throughout a city. They require a technological infrastructure, and promote inter-related pedestrian and bicycle use. Motion information at a kiosk was identified to cause a change in digital display information from public information to one specific to the private user. The research tested low-cost sensor technologies to achieve this motion awareness at the street level, and propose a design opportunity for responsive experiences at a human scale.

The approach to develop the prototype test bed kiosk included three phases:

\subsubsection{Design and urban experience}

Design criteria were developed considering interface design and the challenges in outdoor public spaces. Human interaction design with situated technology in public spaces versus interaction on a mobile phone provides significant challenges of content, viewing distance and orientation. Viewing orientation considered different display heights based on age and ambulatory abilities. Display size and kiosk sensor array was also designed with the necessary criteria to identify people, bikes and vehicles.

\subsubsection{Mockup, material sourcing and build}

Design and fabrication were managed within the limited time of the grant period.

Precedent kiosks were studied and design criteria evaluated; 2D and 3D drawings and visualization were done for design and construction purposes. User interaction was studied both in scaled drawings and with 1:1 full-scale tests to inform interaction location and display orientation and proportions. Design criteria and existing expertise were used to source a touch display, stand and enclosure material for later testing. The enclosure was tested with cardboard mockups to test user focus on the display interface and protect it from environmental conditions such as glare and light rail during testing deployment. 


\subsubsection{Hardware and software testing}

Hardware and software testing was first done in lab conditions. Design criteria listed above was used to identify low-cost sensors, software and coding language. Sensor configurations were engineered, drawn and tested in various conditions in the lab. Coding was done to use the sensors to capture ambient lighting conditions and proximity for motion sensing. Test rigs were developed for outdoor testing of hardware and software. The assembled sensor array, microprocessor and computer, touch display and enclosure were disassembled and reassembled outdoors for approximately four hours for on-site user testing for proximity and display change sequencing.

The approach was developed to create a first-generation prototype test bed within the budget and time constraints of the grant to understand interactive kiosk design with initial tests. In addition, a functioning test bed was a tool to collect data for future tests of transit use, interaction design and urban experience feedback. 


\subsection{METHOD}

The phased approach of design, fabrication and testing listed above provided a framework for the design process. The principle investigators, partnering with a University of Oregon (UO) Digital Scholar Center graduate research assistant and undergraduate assistants, met in the UO Urban Interactions Lab (UIxD) and used the adjacent outdoor pedestrian and bike paths for testing. Design drawings, hardware and software development, mockups and assembly were primarily done in the UO UIxD Millrace Lab space. Fabrication and construction work was done at the nearby UO Millrace Shop.

\subsection{DESIGN PROCESS}

From a design standpoint the primary goal of this test bed was to create a flexible hardware platform that would allow us to examine a range of current and future cases. This created a challenge in scoping out the actual build specifications that ultimately were used in the design, sourcing and fabrication of the working prototype. Although this prototype is framed within the activity of bike share sites, we identified a range of potential applications that went beyond the standard transaction and rental experience encountered at a bike share location.

\subsubsection{Interaction objectives for physical prototype}

Street-level technology has the ability to provide a wide range of interactions beyond those found with commercial or transit transactions. With the increased integration of multi-touch displays and a range of sensing technology, these new and emerging kiosks will increasingly support the traditional tasks associated with public transit (ticket purchasing, timetables, etc.) as well as provide public displays of information and personalized wayfinding. Challenges arise with converging analog and touchscreen functionality into a singular system. In particular, we researched the integrated function between public display and private interface.

When we approached the prototype's design, we leveraged sensing technology to better read the ambient activities occurring around the kiosk to respond to and potentially change its mode from public to private kiosk. Much of the prototype and testing was in support of this new method of interaction coupling sensor input with screen-based output. This was the primary platform that was built and tested during the funded project period. Additional input and output components were integrated into the test bed to account for future case testing, with a primary focus on measuring pedestrian proximity and movement.

\subsubsection{Main criteria for prototype test bed:}

1) Create a flexible hardware platform with appropriate direct and ambient interface components;

2) Make the prototype flexible enough to accommodate future case testing; and 
3) Provide appropriate accessibility for standing/walking pedestrians as well as seated wheelchair users.

\subsubsection{Current test bed design (prototype) - input/output system components}

Ambient/User - Movement \& Proximity (Input):

1) Pedestrian(s) movement corridors (individual, groups)

- Sensors assorted (IR motion, ultrasonic, RGB-D camera)

Direct User Interfaces (Input):

1) Multi-touch screen display

2) Card swipe

3) RFID reader (tag, phone, etc.)

Direct (Output):

1) Multi-touch screen display

\subsubsection{Future test bed (prototype) - input/output system components}

Ambient/Environmental (Input):

1) Sound (traffic, pedestrians, ambient acoustic levels, etc.)

2) Light (sunlight, artificial light)

3) Environmental assorted - Natural (humidity, temperature, barometric pressure)

4) Environmental assorted - Artificial (pollution, particulates, etc.)

Ambient/User - Movement \& Proximity (Input):

1) Pedestrian(s) movement corridors (individual, groups)

- Web camera

2) Bicycle movement corridors (individual, groups)

- Sensors assorted (IR motion, ultrasonic, RGB-D camera)

- Web camera

3) Personal vehicle movement corridors (individual, groups)

- Sensors assorted (IR motion, ultrasonic, RGB-D camera)

- Web camera

4) Public transportation movement

- Sensors assorted (IR motion, ultrasonic, RGB-D camera)

- Web camera

Direct User Interfaces (Input):

1) Multi-touch screen display

2) Voice

Direct (Output):

1) Multi-touch screen display

2) Sound/Audio

3) Lighting assorted

4) Printed transaction receipt 


\subsubsection{Accessibility and human factors}

The primary interface component utilized in this prototype kiosk is the multi-touch screen display. Early research went into identifying an appropriate height and orientation for this display. Two methods were utilized to refine these height requirements.

1) The first method mined the existing anthropometric and human factors data with respect to "line of sight" and "reach." Line of sight refers to the height at which a human's eyes naturally gaze across a horizontal plane, and was an important criterion when we considered what public messages to be viewed at a distance and also provide visual data to be interacted with at close range. Reach was the accessible and comfortable distance at which a user could directly touch and interact with the display. Both line of sight and reach were examined for people standing and in wheelchairs.

2) After collecting the respective data and visualizing this over a range of kiosk heights, we created paper and cardboard mockups to physically explore these heights with three different screen sizes (32, 40 and 50 inches). After these quick mockups it was determined that the largest screen would provide for the biggest degree of interaction opportunities and alleviate reach issues that would be encountered by users in a seated position (wheelchair). Sourcing of a multi-touch screen also played into the final dimensionality and orientation of the display. Based on budget and project timing, we ultimately sourced a 46-inch display unit. The final center height for the prototype kiosk screen was set at 54 inches with a bottom edge accessible at 33.5 inches. These final heights provided for the best accessibility between the two user groups for both line of sight and reach.

\section{Line of Sight - Anthropometric Diagram}

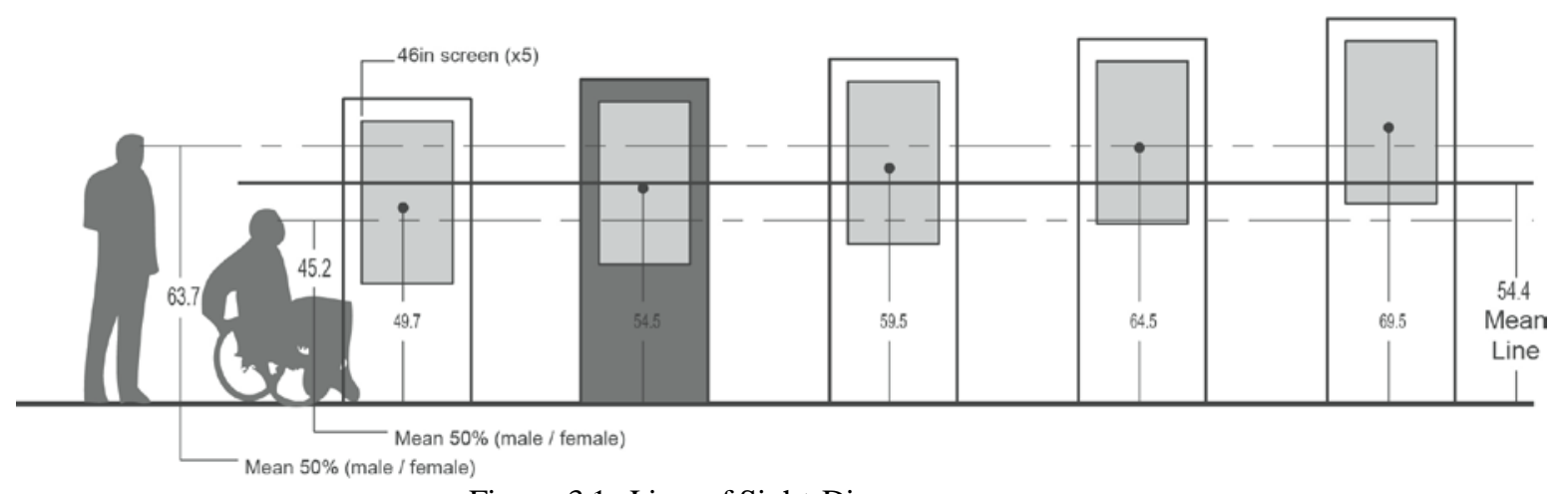

Figure 3.1: Line of Sight Diagram

\subsubsection{Test bed prototype fabrication}

Based on the user interface and human factors criteria established during the initial design phase of this project, a 3D CAD model was created to incorporate these elements into a singular design. The resulting prototype was composed of the display and 
supporting frame, the sensor array (proximity, RGB-D camera), enclosure paneling, processing unit (laptop), and wiring.

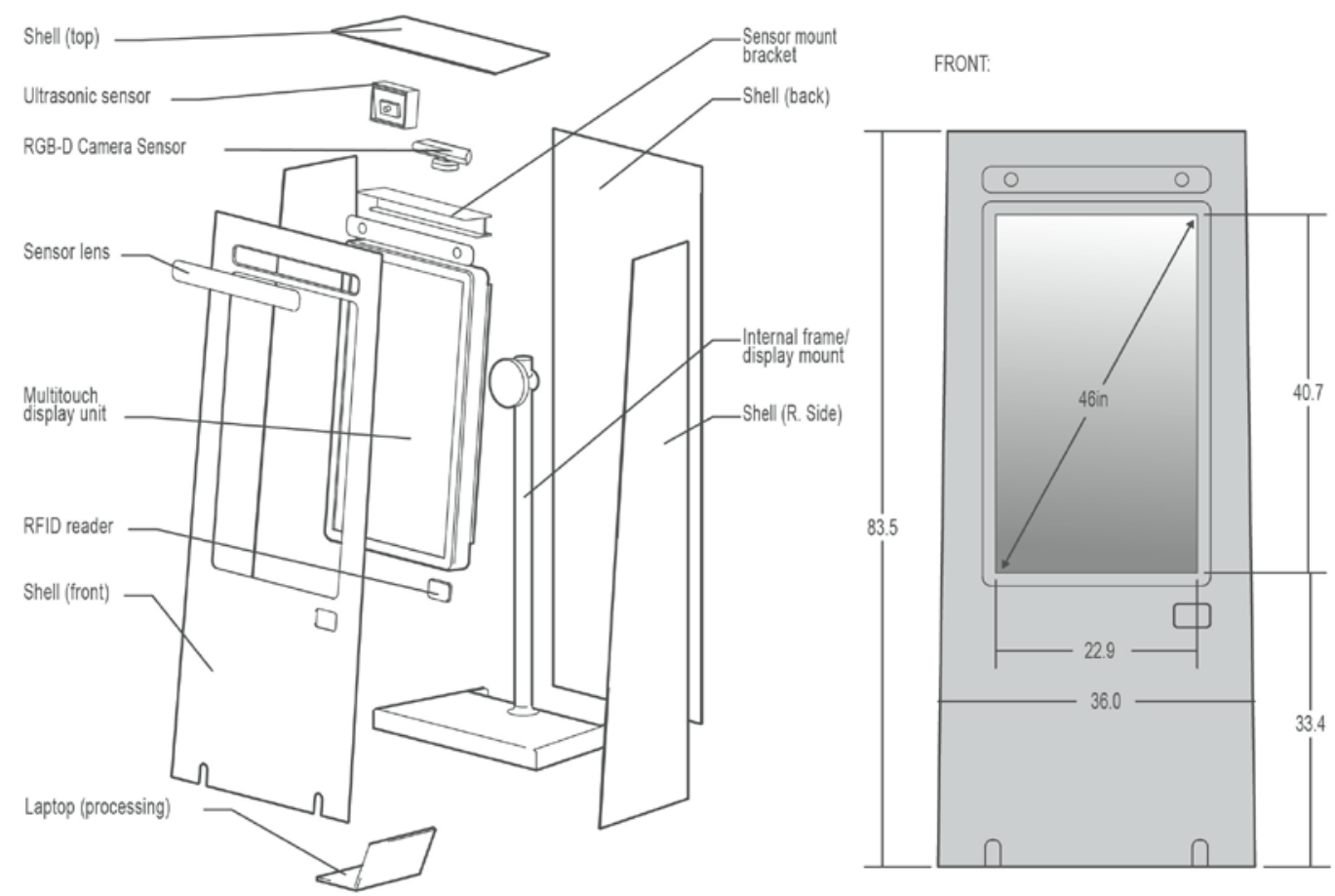

Figure 3.2 Kiosk Fabrication Drawings

Weight and transportation provided an additional design criterion. This test bed is constructed to be easily transported and deployed at various test locations. Individual components were designed to allow for quick disassembly, transport and storage. The enclosure paneling is composed of five sheets of expanded PVC secured together with a Velcro and webbing system. Although the final enclosure does not meet standards to resist poor weather conditions, it provides an appropriate level of concealment for the internal components and sensors to accommodate a perceived kiosk for user studies. See appendix for detailed engineering drawings.
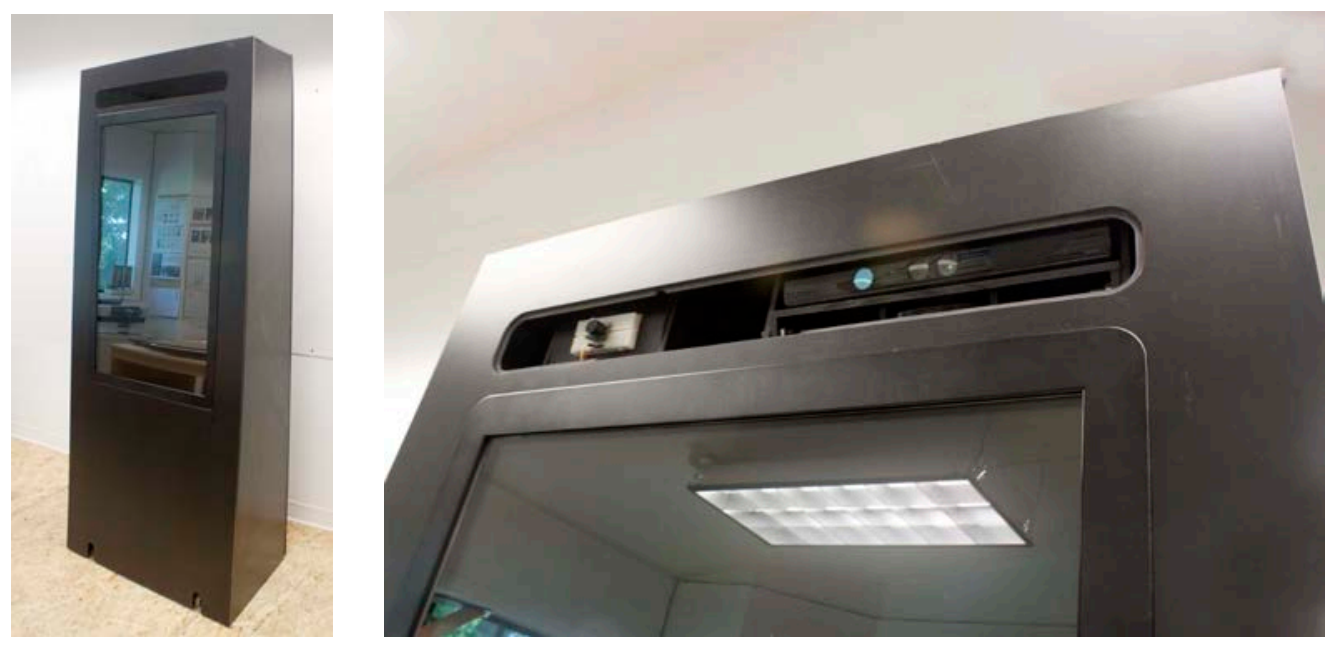
Figure 3.3: Kiosk Fabrication 


\subsection{DATA COLLECTION}

\subsection{CONTROL TESTS}

Initial hardware and software development and testing was done in indoor lab conditions.

\subsubsection{Sensor tests, in-lab and on-test stands}

Sensor tests were performed to meet design criteria with a computer data receiver, an Arduino Uno board for signal processing and various low-cost sensors. Coding was used with Arduino language software, and other coding was used to provide software for the sensor tests. Initial tests were performed at the work design in the lab. Subsequent tests were done with these sensor arrays (no large-touch display, stand or enclosure) to understand the effects of ambient conditions such at light levels, glare and precipitation.

\subsubsection{Passive infrared motion detector (PIR)}

Our initial tests were done with PIR. The PIR sensor uses in-motion detectors to look for changes in the infrared heat energy in a viewing field. It returns a true/false value for motion. In our tests we observed a useful range of 16 feet (Figure 4) and a spread of 90 degrees. However, after activation it has a refresh period before reactivation. It is unable to describe speed, direction or location, or count individuals.
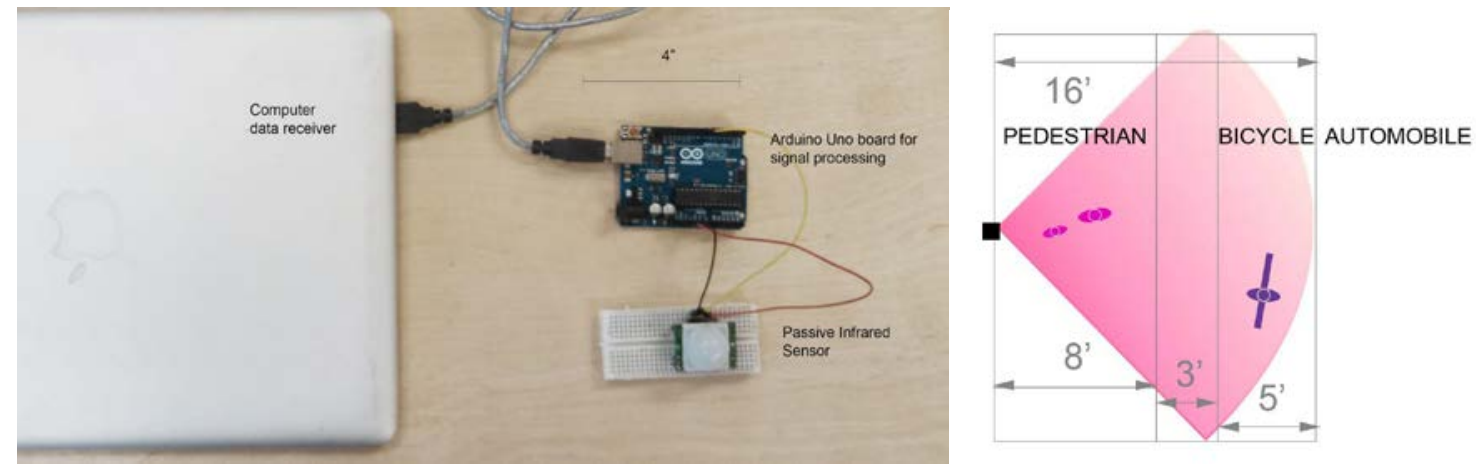

Figure 4.1: Configuration, Range Plan

These sensors monitor and collect data on motion only. A common use for these sensors is for automatic doors where the sensor produces a simple binary signal of motion and thus initiates a door opening sequence. Within the viewable field these sensors examine infrared heat energy and can identify changes in that field. As this sensor was not able to 
produce discreet data about speed, direction or distance, the PIR detector was abandoned as a viable sensing solution.

\subsubsection{Ultrasonic range finding}

A more advanced sensor tested is an ultrasonic rangefinder. It sends sound waves and measures reflected sound by time-of-flight; it returns the range to the nearest object in its detection field. The model we tested, the MaxSonar-EZ1, detects distance effectively between one inch and 125 inches. While proximity is measured in a range cone and cannot distinguish individuals, distance is measured along one axis. To sense location, more detailed sensing is needed.
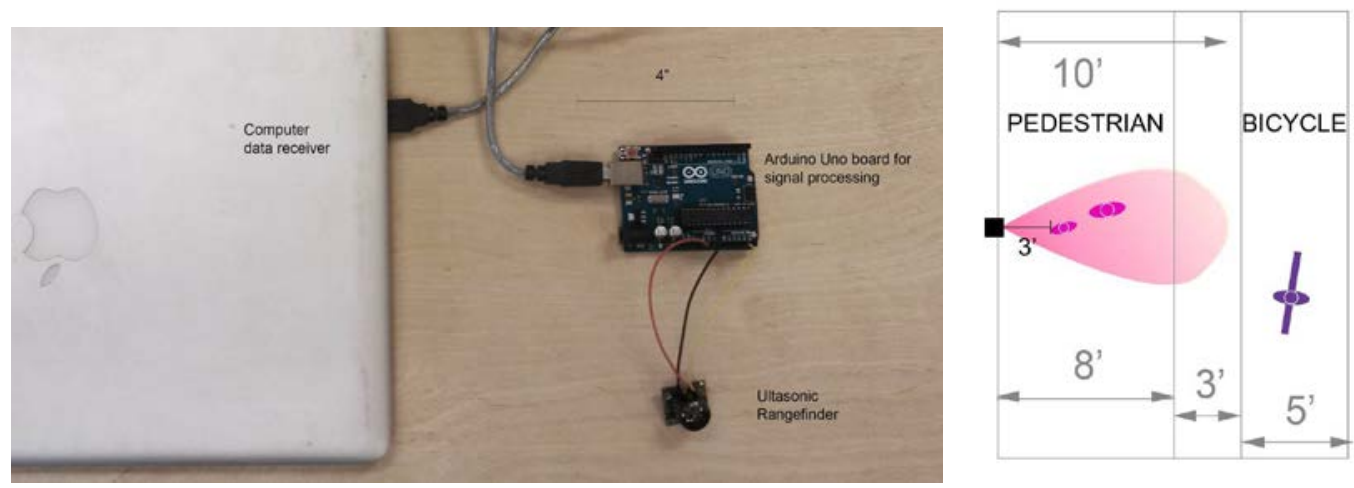

Figure 4.2: Configuration and Range

Ultrasonic rangefinders (transducers) have been used to measure a wide range of things from wind speed to autonomous navigation. Through the production and collection of sound waves, these sensors can measure distance (proximity) and speed quite effectively. Utilizing a MaxSonar-EZ1 in conjunction with an Arduino Uno processing board, we successfully tracked and responded to pedestrian movement within a 10-foot range. However, our ultrasonic sensor did not have the sensitivity to differentiate individuals or successfully separate other non-pedestrian movement (vehicles, bikes, etc.).

\subsubsection{RGB-D camera (Microsoft Kinect)}

To reveal more about pedestrian movement we explored depth field sensors. From one sensor array these sensors generate a 3D scene. We reviewed the Microsoft Kinect sensor as a model for low-cost proximity sensing. Kinect broadcasts a grid of near-infrared light and measures the reflected light with a camera to determine the distance and location of points. We observed the useful zone of Kinect to be within a sensible region, 20 feet deep and 40 degrees wide (Figure 6). Each pixel in a 640x480 image returns a color value and an $\mathrm{x}, \mathrm{y}$ and $\mathrm{z}$ value. 
Kinect has software that recognizes a pattern in the depth field visualized as colored image and wire-frames.. This processing is known as "computer vision." By tracking the center point of each recognized actor, we can now sense location, direction of movement, speed, and traffic volume. Positioning a field sensor at eight feet above individuals, we found a way to maximize the view field (Figure 7). Looking across the described lanes of activity, one sensor can survey different types of activity and categorize between pedestrian, bike or vehicle. Data is calibrated to location, translating our view to a Cartesian mapping, and produces readings similar to other pedestrian tracking tools.
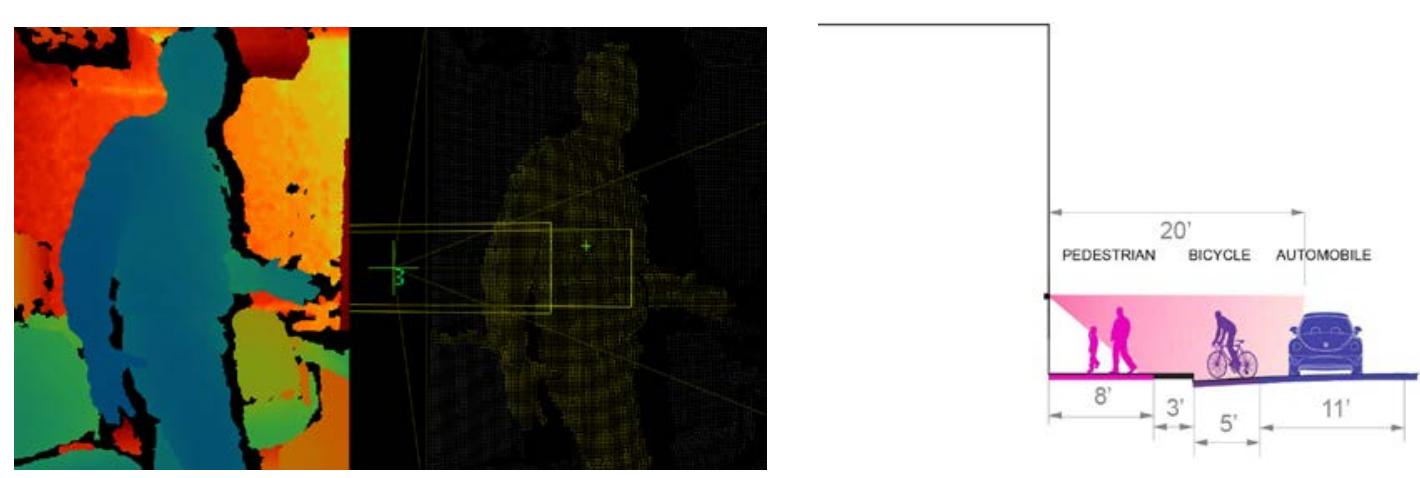

Figure 4.3: Kinect Debug Depth Field and Point Cloud Figure 4.4: Placement of Sensor in Section

The benefit of this motion sensing device is that it has the ability to track and isolate individual targets in the field of view. Although this has currently proved to be the most effective initial solution, the infrared laser on the sensor array shows a high level of sensitivity to ambient light conditions that vary at exterior and street-level locations.

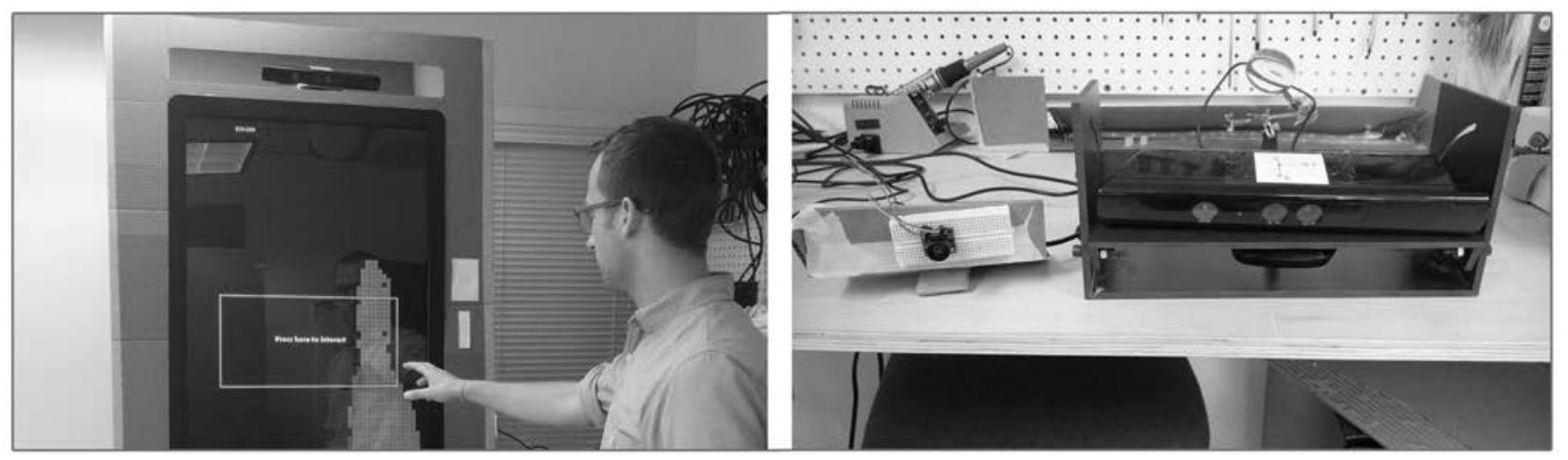

Figure 4.5: Test Rig with Touchscreen Display 


\subsubsection{Ongoing and future studies}

For application with pedestrians and bikes we would propose a depth-field sensor be developed with unique characteristics, becoming more cost-effective and task-specific. It would not require many components found in Kinect, like microphones or motors, but could achieve sensing goals with less resolution and simpler software but increased range. Connection would be made not through a computer USB but existing bike share infrastructure. This could reduce the form, making it simpler for urban deployment. Manufacturing advances like small-order printed circuit boards, Arduino prototyping, 3D printing, and crowdsourcing promise new opportunities to advance sensor technology at a project scale (Chong, p.1,250).

\begin{tabular}{|c|c|c|}
\hline & $\begin{array}{c}\text { KINECT (v.1) } \\
\text { SENSOR }\end{array}$ & Ideal Sensor \\
\hline Sensing Distance & $16-20$ ' & $\begin{array}{c}20 "+(\text { sidewalk to } \\
\text { road) }\end{array}$ \\
\hline $\begin{array}{c}\text { Degree Vertical } \\
\text { Spread }\end{array}$ & 40 degrees & $<40$ degrees \\
\hline $\begin{array}{c}\text { Degree Horizontal } \\
\text { Spread }\end{array}$ & 60 degrees & degrees \\
\hline $\begin{array}{c}\text { Resolution } \\
\text { Audio Sensing }\end{array}$ & $\begin{array}{c}640 \times 480 \text { pixel } \\
\text { RGB-D field }\end{array}$ & Nopth \\
\hline Communication & $\begin{array}{c}\text { Directional } \\
\text { sensing }\end{array}$ & Bike Share Network \\
\hline Price & USB 2.0 to laptop & $\$$ \\
\hline
\end{tabular}

Figure 4.6: Specifications for Kinect and a New Sensor

\subsection{OBSERVATIONAL USER STUDIES, ON-SITE}

On-site testing provided valuable input for outdoor deployment challenges and user interaction observations. A first pilot study was done to inform more detailed intercept testing to follow. The design, physical fabrication and temporary deployment for testing of a working kiosk weighing YYY lbs and requiring $110 \mathrm{~V}$ power access in public space offered a management challenge of time and personnel resources for a limited Small Starts Grant. The successful adaptations days before the on-site deployment and on the day of the temporary installation provided knowledge that is not possible within a controlled, indoor testing environment, and is necessary for this kind of situated technology that will be measured in public spaces with public interactions. 


\subsubsection{Pilot study: Observed interaction test}

A first on-site test was done to test operability of the physical kiosk, and observe interactions between the kiosk and passing pedestrians and cyclists.

The principal investigators, graduate research fellow and three hourly assistants conducted a pilot test of the prototype test bed kiosk for a pedestrian and bike path located near Franklin Boulevard along the adjacent millrace between Onyx Street to the west and the UO Millrace Studios' access road to the east on May 22, 2014, in Eugene, OR. The deployment of the test bed kiosk until breakdown and return to the nearby lab occurred between 12:30 p.m. and 5:30 p.m. The pilot test of observed interactions took approximately 40 minutes to complete.

Members of the research team documented the interaction between passing pedestrian and bike users, the change of display information, and any physical touchscreen interactions between the users and the kiosk. The data was recorded by hands-on, prepared geospatial plans of distances and degrees of interactions. The surveys were collected and processed for analysis. Deployment challenges such as HDMI cable failure and replacement, location selection and interaction limitations were noted.

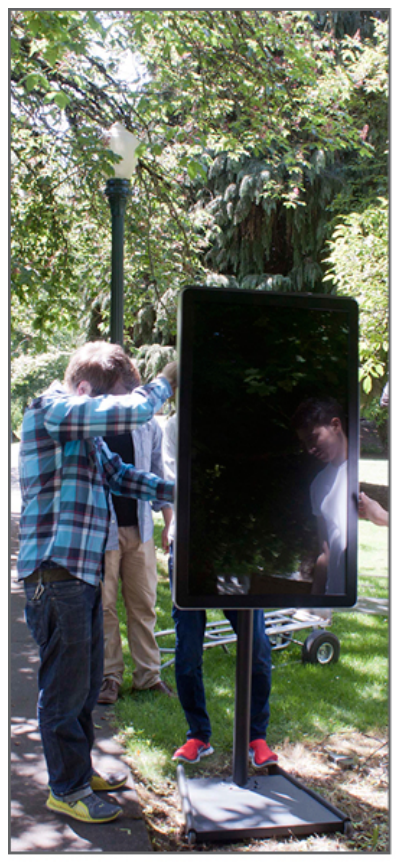

1) Stand \& display assembly

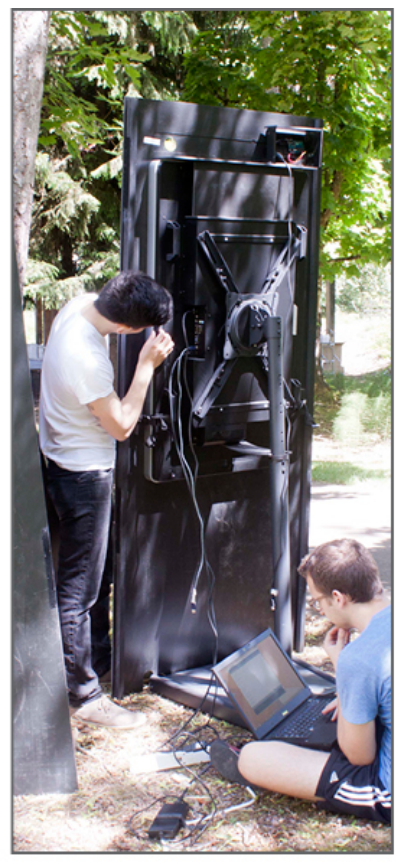

2) Sensor \& processing wiring

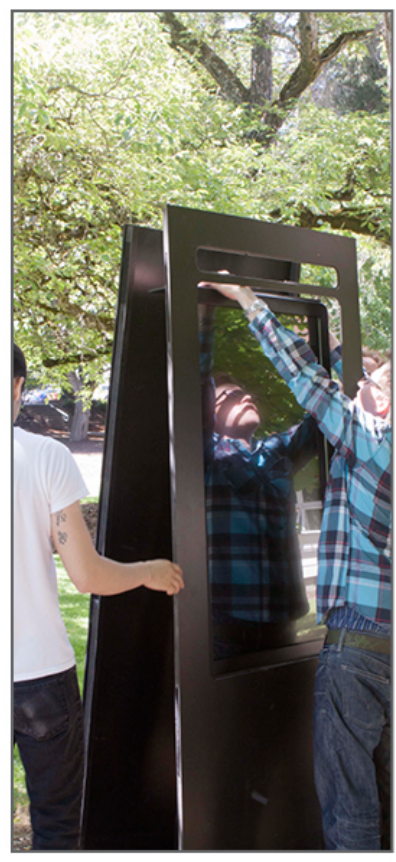

3) Enclosure assembly

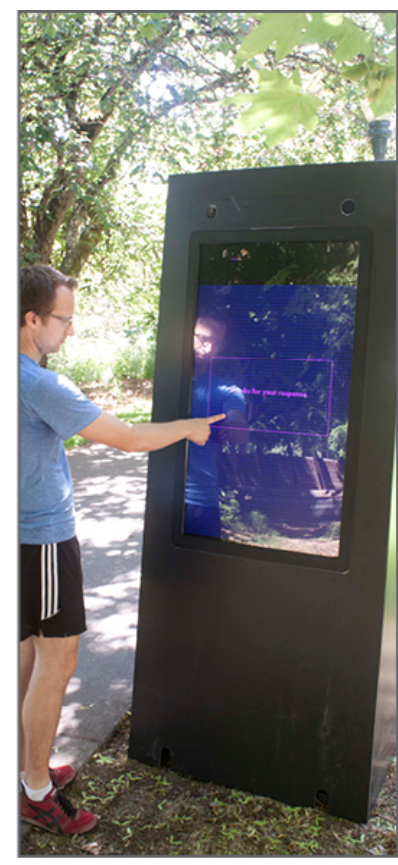

4) Sensor \& display test

Figure 4.6: Pilot Test Deployment 


\subsubsection{Future tests}

\subsubsection{User studies}

Future tests will include an intercept test to survey pedestrian and bike users in their engagement with the kiosk. Subjects will be observed from a distance to ensure neutral potential interaction with the kiosk. Subsequent intercept interviews will take place to cue qualities of user interaction and observations they had with the information being displayed and the effectiveness of the interaction design.

\subsubsection{Identification of pedestrians, bikes and vehicles}

Additional testing is planned that will include identification and proximity capabilities between individual pedestrians, groups, bikes and vehicles. Inclusion of a newly released, next-generation Microsoft Kinect may be used with that test to overcome previous challenges the existing Kinect presented, including ambient, bright light and glare interference. The test location may be performed on the Millrace Access road or nearby along Franklin Boulevard.

\subsubsection{Urban design theory research}

Long-term future tests will incorporate user selections of urban experiences to inform criteria for subsequent recommendations for a feedback loop to inform community connectivity behaviors between individual members. These interacts would test urban design theory for a taxonomy of urban experiences to manage the classification and patterning between user preferences and possible persona development.

\subsubsection{Collaboration with municipal transit agencies}

Possible collaboration with the City of Eugene Wayfinding Group was discussed with program director Kim Mast and would include in-lab test demonstrations. A deployment in downtown Eugene's Kesey Square may be done to test wayfinding location, display type and user interaction behaviors. The consideration of the test bed kiosk may be informative to understand differences in neighborhood identity, the benefits of dynamic display over static wayfinding information, location and API data feeds from transit operators such as Lane County Transit, the Eugene Airport and Amtrak.

Another discussed collaborator for this prototype test bed kiosk or next-generation kiosk is the Portland Bureau of Transportation, with particular application to a forthcoming public bike share program. A multi-day test deployment in a location such as Portland's central Pioneer Square alongside a bike station kiosk was discussed with previous program director Dan Bower, as well as a recent NITC OTREC General RFP proposal with current program director Steve Hoyt-McBeth.

Collaborative testing was additionally discussed with TriMet, Portland's public transit agency, with the application of a smart-card transit user interface and the new Milwaukie alignment. 


\subsection{ANALYSIS AND FINDINGS}

\subsection{ANALYSIS}

The evaluation of the prototype test bed kiosk may be measured in the evaluation of the data collection and the effectiveness of the design, fabrication and testing analysis.

\subsubsection{Design and build effectiveness}

The purpose of the test bed kiosk was to understand the challenges of building an operating, interactive display portal and to demonstrate the ability to support the inter-changeability of sensor arrays.

\subsubsection{Design process}

The design process may be evaluated in the effectiveness of each of its steps: 1) understanding transit experience in public spaces; 2) human accessibility; 3) screen environment testing; and 4) calibration of ambient sensors. The design process benefitted from careful pre- and post-award planning and sequencing. Control tests that more broadly simulated each of the design criteria above, including outdoor public spaces, access, brightness and calibration, may have made evident challenges experienced in our pilot test. Future-generational test beds should benefit from more varied control testing.

\subsubsection{Current design}

The current design serves its purpose as a test bed for interchangeable parts. This was demonstrated days before the pilot test when the RBG-D Microsoft Kinect sensor performed poorly in specific outdoor ambient lighting conditions and was changed with ultrasonic. The ability to easily open the expanded PVC enclosure, change hardware, recode software, and swap out the sensor aperture lens to include a necessary opening for the ultrasonic sensor all proved as a successful demonstration for the intended adaptable use of the test bed for efficiently testing different components.

An anti-glare film was tested on the touch screen but interfered with the touch sensitivity of the interactions. It was removed for the touch display.

\subsubsection{Future design, weather resistance, portability and other design criteria}

The current test bed enclosure and structure stand were designed to provide "open" or replaceable hardware and software tests. The display screen allows a variety of user interaction positions and orientation. The large 50-inch touch display was very effective to test varied interaction heights and orientation of the information interface. However, 
the kiosk's weight and size limited portability, which would suggest narrowing a more defined orientation for a second-generation kiosk. The relatively heavy weight and large size made the display, stand and enclosure challenging to deploy, resulting in the selection of a nearby on-campus location for test deployment. Future designs would also benefit from greater weather resistance, especially to rain and moisture. The current kiosk is not intended to be left overnight nor unattended, as it is not vandalism proof.

\subsubsection{Sensor effectiveness and future sensor criteria}

The RGB-D Microsoft Kinect technology sensor was identified as the most sensitive and useful sensor indoors when compared with infrared PIR and ultrasonic. The majority of time was spent indoors testing the RGB-D sensor. However, days before the pilot test the RBG-D Microsoft Kinect sensor performed poorly in outdoor ambient lighting conditions. Outdoor ambient light caused interference and almost no user motion or proximity to be measured. A test protocol was considered to select an overcast day for testing, but instead the sensor was changed for the lesssensitive ultrasonic sensor. The sensor change took some days to calibrate, but the replacement sensor worked adequately to activate a change in display screen interface when approached by moving pedestrians and bike users. A next-generation RGB-D Microsoft Kinect recently released to market and designed to better manage highly lit conditions will be tested in the future.

\subsubsection{Subject interaction effectiveness}

Limited interaction was observed during the pilot test that measured interaction effectiveness. The conceptual application of the kiosk for public bike share presumes a required interaction with the kiosk as a card swipe or card reader. This would not only trigger the change in display mode, but would also identify the user and could use a custom or persona-based display to match the known or volunteered behavioral patterns of that specific user or similar users at that time in the system. This presumption of required interaction will be considered in future tests, but the principles investigators still see opportunity in a kiosk interaction that does not require sign-in.

\subsubsection{Location effectiveness and future deployment at urban transit location}

The challenge of test bed weight, size, access to $110 \mathrm{~V}$ power and weather resistance all factored into the pilot deployment location near the fabrication lab location. The pilot location was studied with on-site observation two days before the test to identify a peak period of path location use. The day and time of the pilot was a successful time with multiple users passing by the kiosk. However, a more public test deployment location might expose a more varied type of public transit user rather than on a university campus. A preferred location such as Kesey Square in downtown Eugene, a wide public space with pedestrians, bikes, buses and private vehicles, might better test future identification software formulas.

\subsection{FINDINGS / CONCLUSION}

The development of the prototype test bed kiosk included the design, fabrication and testing for an open platform to understand interaction design and transit use. The investigation of a first 
proximity sensor allowed us to understand: 1) indoor lab versus outdoor public space differences of ambient conditions (light, glare); and 2) user engagement of pedestrians and bike users in public spaces. The interaction with users was done using ultrasonic sensors to activate a more personal-scaled display of information. The overall successful operation of the user interaction pilot test proved the feasibility of developing an interactive kiosk to include ambient environmental condition when interacting with transit users in public spaces. The study revealed important kiosk design criteria: 1) interactive display positioning; 2) sensor conditions; 3) user engagement; and 4) portability and weather resistance.

This research demonstrated the need to coordinate interactive design, computing and urban design in public spaces. Significant challenges were revealed in sensor type, managing fabrication-related timelines, and creating a custom-designed kiosk that allowed new instruments for measuring the interaction of transit users in public spaces. However, the working prototype test bed and ability to swap out sensor arrays for successful engagement with passersby demonstrates the tool's future usefulness in providing information to public transit users and testing how community members may be connected through transit use in urban spaces. 


\subsection{REFERENCES}

L. Bettencourt, José Lobo, Dirk Helbing, Christian Kühnert, and Geoffrey B. West. "Growth, innovation, scaling, and the pace of life in cities."Proceedings of the National Academy of Sciences 104, no. 17 (2007): 7301-7306.

B. Bowerman, , J. Braverman, J. Taylor, H. Todosow, and U. von Wimmersperg. "The Vision of A Smart City." The 2nd International Life Extension Technology Workshop. Paris, 2000.

Calabrese, Francesco, Massimo Colonna, Piero Lovisolo, Dario Parata, and Carlo Ratti. 'Realtime urban monitoring using cell phones: A case study in Rome." Intelligent Transportation Systems, IEEE Transactions on 12, no. 1 2011: 141-151.

“City of Melbourne Pedestrian Counting System” Last accessed March 30, 2014. http://www.pedestrian. melbourne.vic.gov.au/

D. Cuff, M. Hansen, and J. Kang. "Urban sensing: out of the woods. "Communications of the ACM 51, no. 3 (2008): 24-33.

A. Greenfield and M. Shepard. Urban Computing and Its Discontents. New York: Architectural League of New York, 2007.

A. Greenfiel. Against the Smart City. New York: Do Projects, 2013.

L. Jessica, “One Company Is Trying To Count And Track All Of New York City's Pedestrians.” Fast Company, February 12, 2014

N. Nabian, Dietmar Offenhuber, Anthony Vanky, and Carlo Ratti. 'Data dimension: accessing urban data and making it accessible." Proceedings of the ICE-Urban Design and Planning 166, no. 1 (2013): 60-75.

C. Ratti. The Copenhagen Wheel. The SENSEable City Lab, 2009

M. Shepard. Sentient City: Ubiquitous Computing, Architecture, and the Future of Urban Space. Cambridge: The MIT Press, 2011. 
World Health Organization. 2014.

http:/www.who.int/gho/urban_health/situation_trends/urban_population_growth_text/en/ (accessed April 2014). 


\subsection{APPENDICES}

\subsection{APPENDIX A-1: TEST BED PHOTOS}

\subsubsection{Mockup}

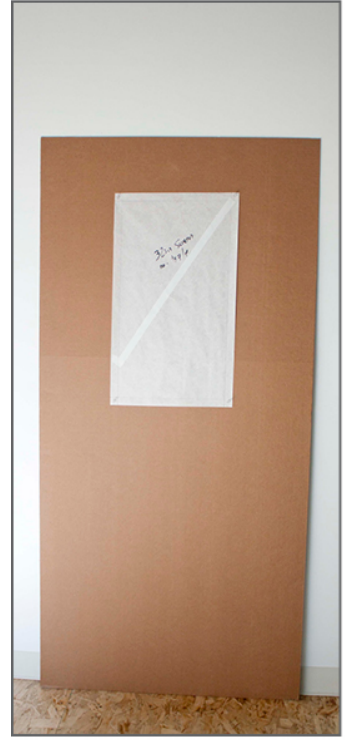

32 " screen mockup

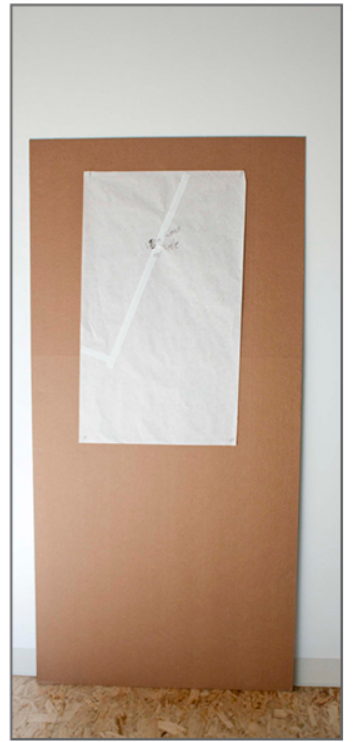

40 " screen mockup

\subsubsection{Display Screen}

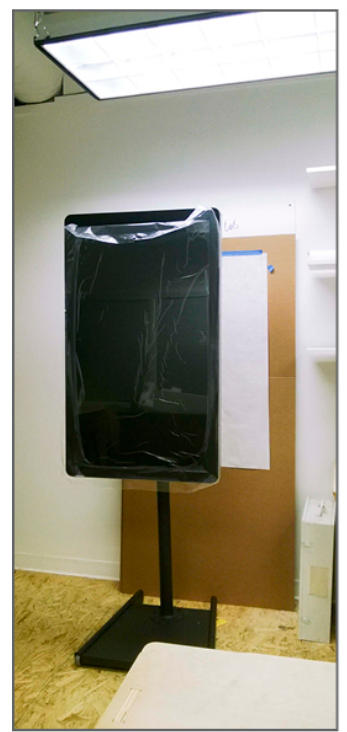

Display and stand

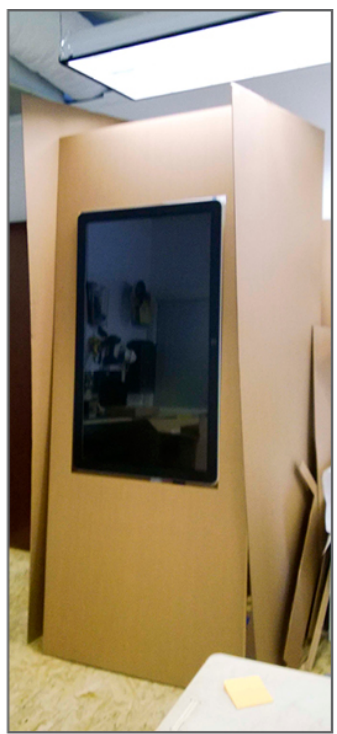

Carboard shell and patterning

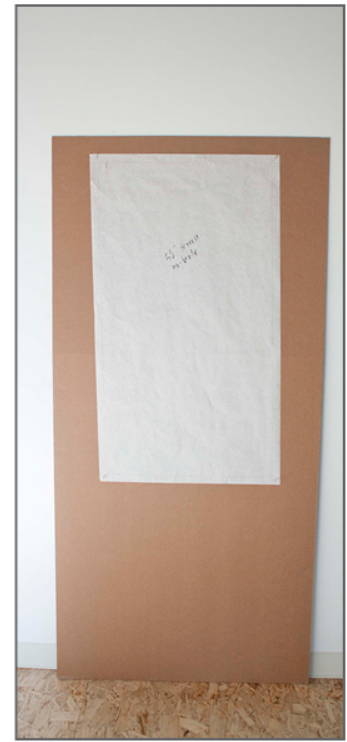

50 " screen mockup

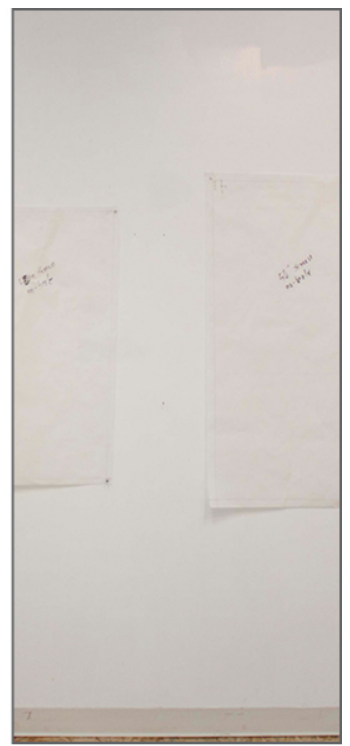

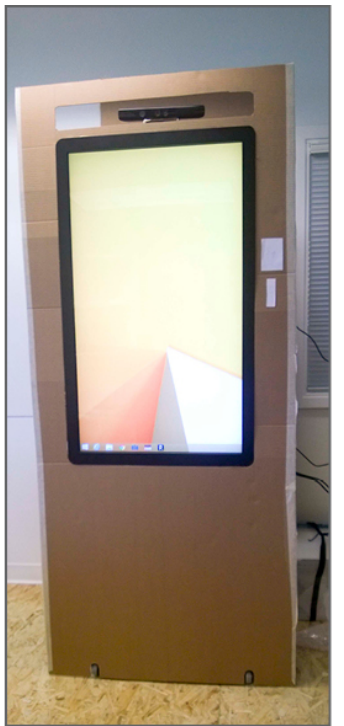

Completed carboard shell

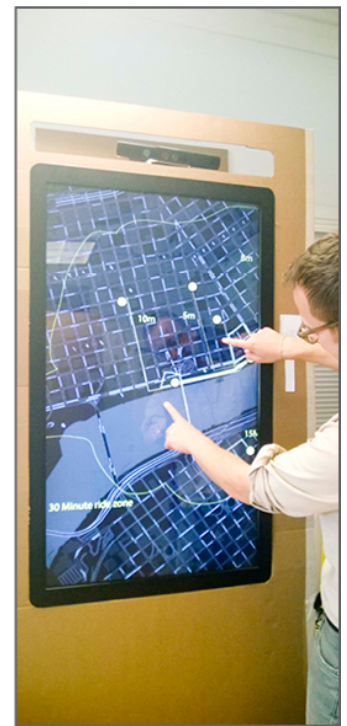

Initial testing with cardboard shell 


\subsubsection{Test Stand, Sensors and Arduino Micro Processor}

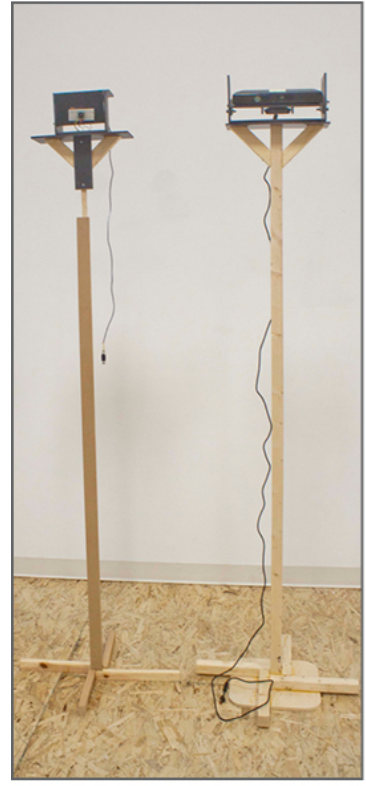

Sensor height test stands
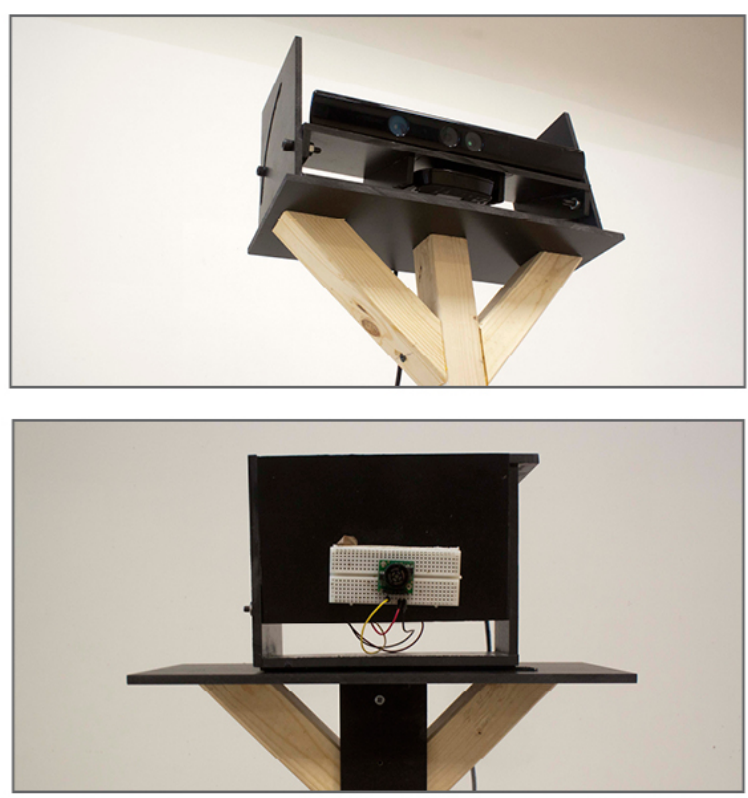

RGB-D camera \& ultrasonic randge finder

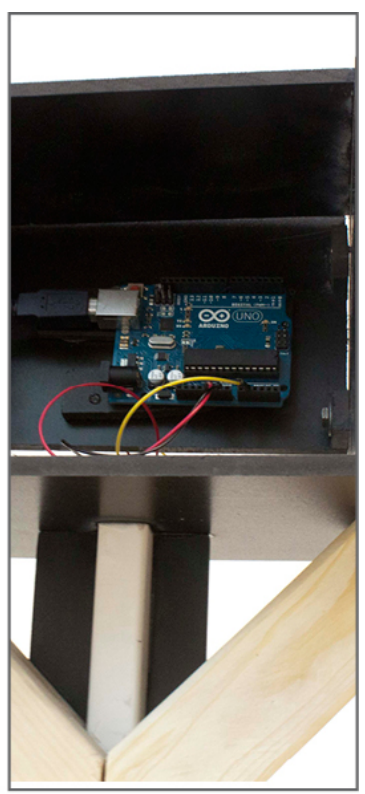

Arduino processing for ultrasonic range finder 


\subsection{APPENDIX B-1: TECHNICAL DRAWINGS}

